\title{
Casar ou não casar? Motivos e expectativas com relação ao casamento
}

To marry or not to marry? Motives and expectations in relation to marriage

¿Casarse o no casarse? Motivos y expectativas con relación al matrimonio

\author{
Eliana Piccoli Zordan* \\ Denise Falcke ${ }^{* *}$ \\ Adriana Wagner ${ }^{* * *}$
}

\begin{abstract}
Resumo
$\mathrm{O}$ casamento tem sido alvo de intensos questionamentos, devido às transformações nas suas características. Do modelo tradicional às diversas formas de casamento atuais, observam-se mudanças tanto nos papéis conjugais como nas expectativas em relação à união conjugal. Este estudo teve por objetivo identificar motivos e expectativas de adultos jovens frente ao casamento. Para tal, aplicou-se um questionário em 197 participantes, com idade entre 20 e 31 anos, residentes no Rio Grande do Sul. O instrumento teve três partes: 1) dados sociodemográficos; 2) questôes sobre projetos vitais e motivos para o casamento, elaboradas para esse estudo; 3) uma questão sobre expectativas, traduzida e adaptada do estudo de Barich e Bielby (1996). Os resultados revelaram que as variáveis que definem a escolha pelo casamento nessa população envolvem aspectos de maior subjetividade (amor, companheirismo e afinidade), assim como coexistem permanências, relacionadas ao modelo tradicional, e mudanças, já características de um novo casamento.
\end{abstract}

Palavras-chave: casamento; motivos; expectativas.

\begin{abstract}
Marriage has been the target of intense questioning due to transformations in its characteristics. From the traditional model to the various forms of present-day marriage, one can observe changes in conjugal roles as well as in expectations related to it. This study aimed to identify the
\end{abstract}

\footnotetext{
Texto recebido em outubro de 2008 e aprovado para publicação em agosto de 2009.

Mestra em Psicologia Clínica pela Pontifícia Universidade Católica do Rio Grande do Sul, professora titular da Universidade Regional Integrada do Alto Uruguai e das Missōes - URI, e-mail: epzordan@uri.com.br.

** Doutora e mestra pela Pontifícia Universidade Católica do Rio Grande do Sul, atualmente é professora do Programa de Pósgraduação e do Curso de Psicologia da Universidade do Vale do Rio dos Sinos - Unisinos, e-mail: dfalcke@unisinos.br.

${ }^{* *}$ Doutora em Psicologia Social pela Universidad Autonoma de Madrid, professora adjunta do Instituto de Psicologia e do Programa de Pós-graduação em Psicologia da UFRGS e coordenadora do Núcleo de Pesquisa Dinâmica das Relações Familiares - PUC RS, e-mail: adriana.wagner@cnpq.br.
} 
motives and expectations of young adults facing marriage. For such, 197 participants between 20 and 31 years of age, living in Rio Grande do Sul, completed a questionnaire. The instrument contained three parts: 1) socio-demographic data; 2) questions regarding vital projects and motives for marriage, elaborated for this study; 3) one question concerning expectations, translated and adapted from a study by Barich and Bielby (1996). Results revealed that the variables defining the choice for marriage in that group involved aspects of greater subjectivity (love, companionship and affinities). They also pointed out the co-existence of permanent aspects, related to the traditional model, and changes, characteristic of a new marriage model.

Keywords: Marriage; Motives; Expectations.

\section{Resumen}

El matrimonio sufre intensos cuestionamientos, debido a las transformaciones de sus características. Desde el modelo tradicional hasta las diversas formas de matrimonio actuales, se observan cambios en los papeles conyugales y en las expectativas referentes a la unión conyugal. El presente estudio tiene como objetivo identificar motivos y expectativas de adultos jóvenes sobre el matrimonio. Por este motivo se hizo una encuesta a 197 participantes, entre los 20 y los 31 años, residentes en Rio Grande do Sul. El instrumento tuvo tres partes: 1) datos sociodemográficos; 2) cuestiones sobre proyectos vitales y motivos para el matrimonio, elaboradas para ese estudio; 3) una cuestión sobre expectativas, traducida y adaptada del estudio de Barich y Bielby (1996). Los resultados revelaron que las variables que definen la elección del matrimonio, en esa población, involucran aspectos de mayor subjetividad (amor, compañerismo y afinidad), así como, coexisten permanencias, relacionadas al modelo tradicional, y cambios, ya características de un nuevo matrimonio.

Palabras-clave: matrimonio; motivos; expectativas

\section{Casar ou não casar? Motivos e expectativas com relação ao casamento}

A instituição "casamento", ao longo do tempo, tem sido moldada pelas determinaçôes econômicas, sociais, culturais, de classe e gênero (Araújo, 2002). Definido no dicionário como "ato solene de união entre duas pessoas de sexos diferentes, capazes e habilitadas, com legitimação religiosa e, ou, civil" (Ferreira, 2004), já traz implícito, em sua conceituação, uma série de características que têm sido questionadas na contemporaneidade. Por exemplo, nesse conceito, ficam expressos os pressupostos da formalidade, da 
união heterossexual, do estado de aptidão e competência dos envolvidos e da necessidade de autorização civil e, ou, religiosa. Será que essa continua sendo a visão de casamento atualmente?

Historicamente, o surgimento do casamento como instituição esteve ligado à regulamentação das atividades de base biológica: a reprodução e o sexo. Durante muito tempo, assumiu a função de legitimar a perpetuação da espécie (Saraceno, 2003). Ao longo da história, no entanto, o casamento assumiu outras funçõos de ordem econômica e social. Mais recentemente, a evolução social, a emancipação feminina, a revolução sexual, o aperfeiçoamento dos métodos anticoncepcionais e das técnicas de reprodução, entre outros fatores, têm modificado o conceito e a posição ocupada pelo casamento em nosso contexto.

Enquanto que, até os anos 70, a constituição da família parecia orientarse por um modelo único de família nuclear tradicional, esta caracterizada pelo casamento heterossexual indissolúvel e pelos papéis do homem como provedor e da mulher como mãe e dona de casa, atualmente, as pessoas adquiriram autonomia nas relações afetivas, na sexualidade, na reprodução e no trabalho. As mulheres estão optando por casar e ter filhos mais tarde, de modo a garantirem o seu futuro profissional. Nesse sentido, o que caracteriza o casamento no início do século XXI é a pluralidade de modelos de conjugalidade.

Nesse contexto, encontramos novos conceitos de casamento. Por exemplo, Severino (1996) chama de casamento a determinação de dois indivíduos de conviverem numa relação estável e que implica assumirem compromissos mútuos, oferecendo reciprocamente suporte para as necessidades sociais, afetivas e sexuais. Complementando essa ideia, Gomes e Paiva (2003) afirmam que o casamento na Pós-modernidade deve estar ligado a uma noção de mutatividade, transformação, flexibilidade em relação ao novo e ao diferente, destacando que esse deve constituir-se num espaço de desenvolvimento interpessoal e de criatividade.

Apesar dessas mudanças, no âmbito da Psicologia, ainda se considera a importância do casamento para o bem-estar das pessoas, colocando-o como uma das tarefas da adultez (Erikson, 1994; Bee, 1997; Carter \& McGoldrick, 2001; Féres-Carneiro, 2003; Morris \& Maisto, 2004). Mesmo assim, é importante levar-se em conta que o casamento tem assumido outra posição no ciclo evolutivo vital das pessoas, pois os homens e as mulheres estão iniciando sua vida sexual mais cedo e casando-se mais tarde, permanecendo mais tempo na casa paterna (Wendling, 2002; Henriques, Jablonski \& 
Féres-Carneiro, 2004; Silveira \& Wagner, 2006). Alguns convivem com o namorado ou namorada na casa paterna, coabitam em domicílio separado das famílias de origem e, ou, têm várias experiências conjugais antes de decidir-se pelo casamento. Observa-se também que, atualmente, há um prolongamento da fase de adulto jovem (Carter \& McGoldrick, 2001), que, no contexto do nível sociocultural médio brasileiro, parece estar associado à percepção de dificuldade de inserção no mercado de trabalho e de obtenção de salários melhores aliada a seguir usufruindo o conforto, da segurança e do pertencimento que a casa dos pais proporciona (Silveira \& Wagner, 2006; Henriques, Féres-Carneiro \& Magalhães, 2006).

Nesse sentido, pesquisa realizada em Porto Alegre, no final da década de 1990, com adolescentes de 12 a 17 anos, de nível socioeconômico médio, estudantes de escolas particulares e públicas, constatou que o casamento já não ocupa um lugar de destaque entre os projetos de vida dos jovens. Seus planos estão mais voltados para a busca da felicidade, da realização pessoal e da realização profissional (Wagner, Falcke \& Meza, 1997). Da mesma forma, outro estudo do mesmo período, realizado com 943 adolescentes entre 14 e 18 anos de sete capitais brasileiras constatou que o casamento está nos planos de vida de $42,4 \%$ deles e, para $29,3 \%$, só está se surgir um grande amor. Casar não estava no plano de $13,1 \%$; para $13,0 \%$, pode haver casamento ou morar junto, tanto faz; e 2,1\% não responderam (Zagury, 1999).

Investigações com adultos jovens da população brasileira têm enfatizado as tensões entre individualidade e conjugalidade (Féres-Carneiro 1997, 1998, 2003) e o espírito de individualismo que predomina nas relações (Jablonski, 2005). Nesse momento histórico-social, os interesses individuais dos cônjuges se sobrepõem ao interesse social, havendo uma maior valorização da subjetividade. Paralelamente, houve um declínio do casamento como projeto principal, surgindo projetos variados e multidimensionados (Coelho, 2000; Orsolin, 2004).

Essa valorização do sujeito como ser diferenciado, buscando a felicidade e a realização pessoal, sexual e profissional, confirma a ênfase na busca de individuação (Marodin, 1997; Rossi, 2003). Ainda considerando aimportância dos aspectos individuais, desde meados dos anos 90 , pesquisadores enfatizam que é amplamente aceito que o objetivo do casamento contemporâneo é a satisfação das necessidades de intimidade de cada um dos cônjuges (Rampage, 1995; Féres-Carneiro, 1998; Magalhães, 2003). A conjugalidade contemporânea adota como ideal a preservação da autonomia individual, equilibrando a manifestação dos "espaços para a individualidade" com a preservação do "solo do casal", isto é, tempo e, ou, espaço compartilhados. 
$\mathrm{Na}$ convivência conjugal, surgem como valores significativos a intimidade e a privacidade a serem dosadas, adequadamente, para preservarem a autonomia e a liberdade que são essenciais (Heilborn, 1995, 2004).

No casamento contemporâneo, os ideais do amor romântico, de que a união é única e eterna, tendem a fragmentar-se, principalmente, devido à emancipação e à autonomia das mulheres. Hoje, os parceiros não aceitam que o casamento não corresponda às suas expectativas de felicidade, prazer, compreensão mútua e companheirismo, sendo o rompimento conjugal cada vez mais frequente (Féres-Carneiro, 1998; Straube; Gonçalves \& Centa, 2003). Corroborando essa ideia, Jablonski (2001) considera que a sociedade cria nos indivíduos uma expectativa muito difícil de ser alcançada, ao tornar sinônimos amor-paixão e casamento, gerando desejos que não se poderão cumprir. Nessa perspectiva, é importante ressaltar que o sentido, os motivos, as expectativas, as práticas referentes ao casamento e à conjugalidade variam conforme o contexto sóciohistórico-cultural e a etapa do ciclo vital dos indivíduos.

Assim, observa-se a coexistência de modelos tradicionais de casamento e novas formas de amar e relacionar-se. Estas estão sendo construídas para responder às exigências de uma sociedade em que os valores e as regras econômicas e sociais estão sempre em mutação (Araújo, 2002; Diniz Neto \& Féres-Carneiro, 2005). O que se constata atualmente é um menor número de uniōes formais, mas não de união de maneira geral (Paterniani, 1997; Goldenberg, 2004).

Entre as características dos casamentos atuais, além da relação igualitária entre os parceiros, é ressaltada a valorização do companheirismo e da cumplicidade (Goldenberg, 1991, 2004). Saraceno (2003) acrescenta ainda a não obrigatoriedade de procriação, afirmando que a falta de amor num casamento é que constitui uma espécie de aberração.

Estudiosos do tema (Garcia \& Tessara, 2001; Haddad, 2006) afirmam que, no contexto contemporâneo, para haver o casamento, é necessário o amor. Este tendo como característica principal a intensidade e não mais a eternidade, bem ao sabor da poesia de Vinícius de Morais (1992): "Que não seja imortal, posto que é chama, mas que seja infinito enquanto dure". Cai por terra, portanto, o peso do "até que a morte nos separe", surgindo a ideia de que a relação entre os envolvidos tenha por eixo, cada vez mais, o desejo recíproco e menos a obrigação (Turkenicz, 1995). Priorizando-se a igualdade e o respeito à mútua individualidade (Costa, 2007).

Essa mudança na concepção dos relacionamentos se evidencia na emergência da superficialidade vincular (Mezan, 2003), caracterizada pela paixão intensa, porém efêmera. Segundo Bauman, essa é a concepção do que 
ele denomina amor líquido, um reflexo da fragilidade dos vínculos humanos na contemporaneidade, que inspira desejos conflitantes "de apertar os laços e, ao mesmo, tempo mantê-los frouxos" (Bauman, 2004, p. 8). Dessa forma, os casamentos tornam-se mais fugazes e, frente às dificuldades da vida em conjunto, é mais comum a dissolução do vínculo do que a perseverança na busca de alternativas para a resolução.

Todas essas transformações implicam em mudanças nos motivos para o casamento. Pesquisas revelam que as pessoas se casam em busca de satisfação sexual, serem atendidas e admiradas, não envelhecerem sozinhas, fugirem da solidão ou mesmo obterem valores materiais e prestígio social (Davis, 1998; Carter \& McGoldrick, 2001; Costa, 2007). Garcia-Veja e Ríos-González (1999) apontaram também o motivo para livrar-se de uma situação familiar incômoda. Na opinião de Branden (2000), questões legais e financeiras podem tornar tal união desejável, ainda que estas não sejam motivações essenciais.

Diferentes perspectivas são esperadas por homens e mulheres com relação ao casamento. Nas relações amorosas, segundo Gray (1997), os homens buscam, principalmente, confiança, aceitação, apreço, admiração, aprovação e encorajamento. As mulheres querem, principalmente, carinho, compreensão, respeito, devoção, validação e reafirmação. Bueno \& Prado (1989) também enfatizam essas diferenças entre o homem e a mulher, afirmando que elas são fundamentais, complementares e necessárias para a formação do verdadeiro par.

No que se refere aos motivos religiosos para o casamento, aqueles que se declaram católicos praticantes são mais claramente desfavoráveis à convivência não matrimonial, quer como modelo alternativo ao casamento, quer como fase precedendo-o (Saraceno, 2003).

Em relação às expectativas sobre o casamento, um estudo realizado com estudantes de escolas secundárias de nível socioeconômico médio nos Estados Unidos, comparando dados obtidos em 1967 e em 1994, constatou que a classificação total das médias para as 11 expectativas consideradas (lugar respeitável na comunidade, crianças felizes e saudáveis, companheirismo, desenvolvimento da personalidade, quantidade de amor e afeição, segurança econômica, relações sexuais satisfatórias, segurança emocional, unidade religiosa e moral, atividades de interesses comuns e manutenção de um lar) foi notavelmente semelhante no período de 27 anos. Permaneceu, em primeiro lugar, o amor e a afeição e, nas últimas posiçôes, unidade moral e religiosa, manutenção de um lar e um lugar respeitável na comunidade, consistentemente, classificados como nono, décimo e décimo primeiro (Barich \& Bielby, 1996). 
Partindo dessa ideia presente na literatura especializada sobre as permanências e mudanças nas relações conjugais na contemporaneidade, este estudo investigou os motivos e expectativas das pessoas em relação ao casamento. Será que os pressupostos sobre as novas uniōes já estão incorporados ou ainda coexistem diferentes perspectivas sobre a conjugalidade? Qual a visão do casamento está refletida na opinião dos adultos jovens? Com base em tais questôes, buscamos identificar os motivos e as expectativas que adultos jovens atribuem para o casamento, verificando a posição do evento entre os projetos vitais dos adultos jovens e comparando os motivos e expectativas de homens e mulheres em relação ao casamento.

\section{Método}

\subsection{Amostra}

A amostra desse estudo foi constituída por 197 participantes, sendo 120 mulheres e 77 homens, com idade entre 20 e 31 anos, por esse período ser definido pelos estudiosos do ciclo vital como adultez jovem (Bee, 1997; Papalia; Olds \& Feldman, 2006). Com a relação à escolaridade, 57,9\% tinham ensino médio completo e $42,1 \%$ tinham ensino superior completo. Do total, 77,2\% estavam trabalhando. Mesmo assim, a ocupação mais frequente foi a de estudante $(27,4 \%)$, o que sugere que mais de um quarto desses adultos jovens ainda estão se preparando para a carreira profissional. A maioria tinha renda entre 1 e 3 salários (47,2\%), enquanto que $23,4 \%$ referiram não ter renda própria. A religião católica predominou significativamente (80,2\%), sendo que $51 \%$ afirmam ser praticantes e $49 \%$ não praticantes. Em relação à condição amorosa, $60,7 \%$ tinham namorado ou namorada e 39,3\% não tinham, o que indica que a maioria tinha um relacionamento estabelecido. Quanto ao tempo de namoro daqueles que tinham namorado ou namorada no momento da pesquisa (123 sujeitos), observou-se um mínimo de 1 mês e um tempo máximo de 10 anos e 4 meses. Do total, 69,1\% dessa amostra já estão namorando entre 1 e 4 anos, o que caracterizaria uma relação duradoura.

\subsection{Instrumento}

Considerando a ausência de instrumentos padronizados que abordassem os fatores que envolvem a escolha pelo casamento entre adultos jovens na contemporaneidade, foi elaborado um questionário composto por três partes: 1 - dados sociodemográficos de identificação; 2 - duas questôes relacionadas aos projetos vitais e aos motivos que levam ao casamento. Estas foram elaboradas com base na revisão da literatura e de entrevistas com casais de 
noivos que estavam preparando-se para casar. Nessas entrevistas, exploraram-se vários aspectos que envolviam os projetos vitais, os motivos para o casamento, a influência das famílias, dos amigos, as expectativas em relação ao casamento e ao futuro; a questão sobre motivos classificou-os em pessoais ou afetivos, familiares, socioeconômicos e religiosos. Para cada uma dessas quatro classes de motivos, elaboraram-se seis alternativas para serem avaliadas por uma escala Likert composta por cinco pontos: concordo totalmente (CT), concordo (C), indeciso (I), discordo (D) e discordo totalmente (DT); e 3 - uma questão sobre expectativas em relação ao casamento usada num estudo realizado por Barich e Bielby (1996). Esta passou por um processo de tradução e adaptação, realizado por três especialistas bilingues da área.

O questionário inicial foi submetido a uma validação semântica, de fidedignidade e de consistência. A subescala de atitudes frente ao casamento, usada por Barich e Bielby (1996), obteve consistência interna média (alpha= $0,65)$. A subescala de motivos criada pela pesquisadora, com base na revisão de literatura e entrevistas com casais de noivos, alta consistência interna (alpha $=0,83)$.

\subsection{Procedimentos para a coleta de dados}

Para a coleta de dados, foram distribuídos 400 questionários em universidades e empresas eleitas pelo critério de conveniência. Os questionários foram entregues em envelopes selados e endereçados à pesquisadora. Retornaram 213 questionários (53,25\% dos distribuídos), sendo que, destes, 16 (4\%) foram excluídos do levantamento por virem incompletos ou em branco ou por participante não se enquadrar efetivamente no perfil da amostra (não ser solteiro, por exemplo).

\subsection{Procedimentos de análise dos dados}

Fez-se inicialmente uma análise descritiva dos dados a fim de conhecer a distribuição das variáveis em estudo. Posteriormente, utilizou-se o Teste $t$ de Student, considerando um nível de significância de 0,05.

\section{Apresentação e discussão dos resultados}

A seguir, serão apresentadas as análises descritivas e comparativas das variáveis em estudo. Inicialmente, para compreender os projetos vitais dos adultos jovens e identificar o lugar do casamento entre eles, apresentou-se uma relação de 21 metas de vida e solicitou-se que assinalassem as que consideravam como as 5 principais para a sua vida. As respostas ficaram assim distribuídas: 


\section{Tabela 1}

Projetos Vitais

\begin{tabular}{|c|c|}
\hline Projetos vitais & Sim \\
\hline 1ㅇ realização profissional & $60,8 \%$ \\
\hline 2ㅇ realização pessoal & $44,3 \%$ \\
\hline 3으 boas condições de vida & $43,5 \%$ \\
\hline 4으 conquistar os sonhos & $37,6 \%$ \\
\hline 5o continuar estudando & $34,2 \%$ \\
\hline 60 ser valorizado profissionalmente & $34,0 \%$ \\
\hline 70 constituir família & $31,4 \%$ \\
\hline 8o bom relacionamento com companheiro ou companheira & $28,4 \%$ \\
\hline 9o ter paz interior & $25,8 \%$ \\
\hline 10 o felicidade ao lado de alguém & $22,2 \%$ \\
\hline 11으 realização espiritual & $21,1 \%$ \\
\hline $12 \circ$ ter filhos & $20,2 \%$ \\
\hline 13ㅇ futuro digno, sem desigualdades & $19,1 \%$ \\
\hline 14으 ter um bom emprego & $17,7 \%$ \\
\hline 150 seguir uma carreira & $17,0 \%$ \\
\hline 160 ter casa & $14,4 \%$ \\
\hline 170 encontrar o amor & $13,0 \%$ \\
\hline 18 o encontrar a felicidade & $12,9 \%$ \\
\hline 19o casar & $9,3 \%$ \\
\hline 200 ser reconhecido socialmente & $7,2 \%$ \\
\hline 21 o ter carro & $5,2 \%$ \\
\hline
\end{tabular}

Observa-se que, nas cinco primeiras posições, predominam projetos relacionados aos aspectos profissionais (realização profissional, continuar estudando, ser valorizado profissionalmente), bem como preocupações com os aspectos materiais (ter boas condições de vida). Essa valorização do aspecto profissional está relacionada, principalmente, com os valores contemporâneos que enfatizam a individualidade, a realização e o sucesso profissional (Coelho, 2000). Aparece, também, entre as primeiras posições, conquistar os sonhos e realização pessoal. A palavra "sonhos" é muito ampla e pode estar relacionada a vários aspectos: profissionais, afetivos, familiares, econômicos, entre outros. Da mesma forma, realização pessoal também abrange um sentido mais global de conquistas.

Considerando todos os projetos vitais apresentados para serem classificados, casar ficou entre as últimas posições, ocupando a décima nona posição entre os 21 projetos de vida apresentados. Além disso, observa-se que foram mais valorizados os itens que mencionavam um relacionamento conjugal, sem se referir ao casamento propriamente dito. Por exemplo, bom relacionamento com companheiro ou companheira ( $8^{\circ}$ lugar $-28,4 \%$ ) e felicidade ao lado de 
alguém (10\% lugar - 22,2\%). Esse dado possivelmente reflita o quanto a vida conjugal pode ser exercida de diferentes formas, desvinculando-se da noção tradicional de casamento.

$\mathrm{Na}$ análise comparativa, não foram encontradas diferenças estatísticas significativas entre os sexos. Tanto homens quanto mulheres indicaram hierarquia semelhante em termos de projetos vitais, o que evidencia uma posição mais igualitária entre os sexos.

Quando perguntados diretamente se desejam casar algum dia, as respostas ficaram assim distribuídas:

\section{Tabela 2}

Desejo de casar algum dia

\begin{tabular}{lll}
\hline Desejo casar algum dia & Frequência & Porcentagem \\
\hline Sim & 182 & $92,9 \%$ \\
\hline Não & 14 & $7,1 \%$ \\
\hline Não respondeu & 1 & $0,5 \%$ \\
\hline Total & 197 & $100 \%$ \\
\hline
\end{tabular}

Chama a atenção que a grande maioria $(92,9 \%)$ deseja casar algum dia, embora isso não tenha aparecido entre os cinco principais projetos. Essa porcentagem foi semelhante à encontrada por Jablonski (2005) nos três períodos em que investigou atitudes e expectativas de jovens solteiros universitários. A maioria dos respondentes em todas as sondagens revelou intenção de casar: 91\% em 1986, 86\% em 1993 e 86,1\% em 2003. Parece que o casamento não é mais tão valorizado socialmente como projeto de vida, apesar de ser uma realização ainda almejada. Esses achados corroboram a afirmação de que o casamento não é mais uma obrigação, mas uma escolha que continua a representar uma condição pretendida (Branden, 2000), talvez em etapa posterior à adultez jovem. Esse dado pode corroborar a ideia da postergação do casamento para que ocorra quando as pessoas já se sintam realizadas profissionalmente. Por isso a maior valorização do sucesso profissional na etapa de vida que foi observada pela pesquisa.

$\mathrm{Na}$ análise comparativa, não foi encontrada diferença significativa entre os sexos. Esses dados sugerem que, atualmente, o desejo de casar, de ter filhos, de constituir família é semelhante em ambos os sexos, não havendo uma maior valorização do casamento e da família pelo sexo feminino, o que, pelos antecedentes históricos, era esperado.

Partindo da definição de motivo adotada para este estudo, de que "é aquilo a que um indivíduo atribui conscientemente às bases de seu comportamento" (Cabral, 2006, p. 212), dividiram-se os motivos para o casamento em 
motivos pessoais ou afetivos, familiares, socioeconômicos e religiosos. Para cada uma dessas quatro classes de motivos, elaboraram-se seis alternativas para serem avaliadas por uma escala Likert composta por cinco pontos: concordo totalmente (CT), concordo (C), indeciso (I), discordo (D) e discordo totalmente (DT). Os resultados da análise dos motivos pessoais são apresentados no quadro a seguir:

\section{Quadro 1}

Motivos pessoais para o casamento

\begin{tabular}{llllll}
\hline Motivos pessoais & CT & C & I & D & DT \\
\hline As pessoas se casam por amor & $23,6 \%$ & $49,7 \%$ & $13,3 \%$ & $11,8 \%$ & $1,5 \%$ \\
\hline Para fugir da solidão & $5,1 \%$ & $46,7 \%$ & $20,0 \%$ & $22,1 \%$ & $6,2 \%$ \\
\hline Porque sentem que combinam & $14,4 \%$ & $62,6 \%$ & $10,8 \%$ & $9,7 \%$ & $2,6 \%$ \\
\hline Porque têm certeza do seu sentimento pelo outro & $15,3 \%$ & $42,3 \%$ & $22,4 \%$ & $14,3 \%$ & $5,6 \%$ \\
\hline Para ter um espaço para o casal & $1,5 \%$ & $38,8 \%$ & $14,8 \%$ & $30,1 \%$ & $14,8 \%$ \\
\hline Para ter relacionamento sexual & $2,1 \%$ & $21,5 \%$ & $9,2 \%$ & $42,6 \%$ & $24,6 \%$ \\
\hline
\end{tabular}

Os motivos pessoais que, na opinião dos sujeitos, justificam o casamento de forma mais intensa são: porque sentem que combinam (77\%), por amor $(73,3 \%)$, porque têm certeza do seu sentimento pelo outro $(57,6 \%)$, o que sugere que o amor, a afinidade, o envolvimento afetivo permanecem como um motivo para o casamento. Também para fugirem da solidão $(51,8 \%)$, confirmando que há geralmente uma reciprocidade e complementaridade das necessidades, anseios e medos que fazem parte da vida a dois (Pincus \& Dare, 1981). Quanto ao motivo para terem um espaço para o casal, observou-se maior dispersão das respostas, o que sugere que esse aspecto tanto pode ser ou não um motivo para o casamento. A maioria dos respondentes discorda de que as pessoas casam para terem relacionamento sexual, o que corrobora a ideia de maior liberdade sexual, não mais vinculada ao casamento como foi em outras épocas. O sexo préconjugal e a coabitação são mais prevalecentes, reduzindo a necessidade do casamento para o exercício da sexualidade (Barich \& Bielby, 1996; Menezes \& Lopes, 2007).

Quanto aos motivos pessoais para o casamento, observou-se diferença estatística significativa nos subitens para fugirem da solidão $(\mathrm{p}=0,034)$ e para terem um espaço para o casal $(0,012)$. Os homens concordam mais com essa afirmativa como motivo para o casamento do que as mulheres. Esses achados parecem estar associados aos dados encontrados por FéresCarneiro (1997) quanto à concepção de casamento que, para os homens, significa constituir família, ter um lar, uma casa, enquanto, para as mulheres, é definido como relação amorosa. 
Em relação aos motivos familiares, os resultados aparecem expressos no quadro a seguir:

Quadro 2

Motivos familiares para o casamento

\begin{tabular}{llllll}
\hline Motivos familiares & CT & C & I & D & DT \\
\hline A família exige o casamento & $9,2 \%$ & $22,1 \%$ & $10,8 \%$ & $40,5 \%$ & $17,4 \%$ \\
\hline A família espera que os filhos se casem & $14,4 \%$ & $64,1 \%$ & $7,2 \%$ & $10,8 \%$ & $3,6 \%$ \\
\hline É importante para os pais que os filhos se casem & $11,3 \%$ & $51,3 \%$ & $14,4 \%$ & $17,9 \%$ & $5,1 \%$ \\
\hline Toda mãe quer que os filhos se casem & $17,0 \%$ & $41,8 \%$ & $13,4 \%$ & $21,1 \%$ & $6,7 \%$ \\
\hline O casamento é um compromisso com os familiares & $8,2 \%$ & $26,2 \%$ & $12,3 \%$ & $39,0 \%$ & $14,4 \%$ \\
\hline O casamento é uma oportunidade para sair de casa & $7,2 \%$ & $20,5 \%$ & $10,8 \%$ & $30,3 \%$ & $31,3 \%$ \\
\hline
\end{tabular}

Observa-se a importância dos valores e expectativas da família como motivo para que os adultos se casem. A maioria concorda que a família espera que os filhos se casem (78,5\%), é importante para os pais que os filhos se casem (62,6\%) e toda mãe quer que os filhos se casem $(58,8 \%)$. No entanto, eles não veem o casamento como exigência da familia (57,9\%), nem como compromisso com os familiares (53,4\%), nem como oportunidade para sair de casa $(61,6 \%)$.

Em relação aos motivos familiares para o casamento, não foi encontrada diferença estatística significativa entre os sexos, o que corrobora a ideia de que as fronteiras entre homens e mulheres têm sido cada vez mais difusas, não sendo mais tão marcadas tais diferenças. Essas respostas evidenciam que o casamento continua sendo esperado pelas famílias, porém não visto como uma exigência pela maioria.

No que se refere aos motivos socioeconômicos, foram oferecidas seis alternativas, e os resultados estão expressos no próximo quadro:

Quadro 3

Motivos socioeconômicos para o casamento

\begin{tabular}{llllll}
\hline Motivos socioeconômicos & CT & C & I & D & DT \\
\hline O casamento oficializa uma união perante a sociedade & $17,9 \%$ & $52,3 \%$ & $8,7 \%$ & $16,4 \%$ & $4,6 \%$ \\
\hline Casar é assumir um compromisso perante a sociedade & $9,8 \%$ & $39,2 \%$ & $11,9 \%$ & $32,5 \%$ & $6,7 \%$ \\
\hline A sociedade espera que as pessoas se casem & $8,2 \%$ & $37,4 \%$ & $20,5 \%$ & $24,6 \%$ & $9,2 \%$ \\
\hline As pessoas se casam por interesses econômicos & $5,2 \%$ & $30,4 \%$ & $28,9 \%$ & $24,2 \%$ & $11,3 \%$ \\
\hline A busca de segurança econômica leva ao casamento & $6,7 \%$ & $33,5 \%$ & $16,0 \%$ & $31,4 \%$ & $12,4 \%$ \\
\hline As pessoas se casam porque têm bens & $3,1 \%$ & $16,0 \%$ & $14,4 \%$ & $45,9 \%$ & $20,6 \%$ \\
\hline
\end{tabular}

Os adultos jovens concordam, na sua maioria, que o casamento oficializa uma uniāo perante a sociedade (70,2\%). Porém as opiniōes estão divididas quanto à sociedade esperar que as pessoas se casem, quanto a casar é assumir um 
compromisso perante a sociedade, quanto à busca de segurança econômica e a interesses econômicos como motivos para o casamento. Esses dados confirmam a opinião de Branden (2000) de que questôes legais e financeiras podem tornar o casamento desejável, porém isso não significa que seja a essência dos motivos para tal união.

Entre os motivos socioeconômicos para o casamento, encontrou-se diferença estatística significativa entre os sexos no item casar é assumir um compromisso perante a sociedade $(0,045)$. As mulheres apresentaram maior concordância do que os homens. Esse achado pode estar refletindo a ideia de que as mulheres ainda se sentem mais cobradas e precisam dar mais satisfações à sociedade em relação ao seu comportamento, estado civil e relacionamentos. Podem indicar também a herança de algumas décadas atrás, quando o valor da mulher estava atrelado a sua capacidade ou incapacidade de casar (Diehl, 2002).

A subescala de motivos religiosos para o casamento obteve os resultados mostrados no quadro a seguir:

\section{Quadro 4}

Motivos religiosos para o casamento

\begin{tabular}{llllll}
\hline Motivos religiosos & CT & C & I & D & DT \\
\hline O casamento é um compromisso com Deus & $13,5 \%$ & $26,4 \%$ & $14,5 \%$ & $29,0 \%$ & $16,6 \%$ \\
\hline Quem tem fé considera o casamento um ato sagrado & $23,5 \%$ & $50,0 \%$ & $10,2 \%$ & $11,2 \%$ & $5,1 \%$ \\
\hline $\begin{array}{l}\text { O casamento é muito valorizado pelas diferentes } \\
\text { religiões }\end{array}$ & $13,0 \%$ & $54,4 \%$ & $20,7 \%$ & $11,4 \%$ & $0,5 \%$ \\
\hline $\begin{array}{l}\text { As religiões que você conhece obrigam o casa- } \\
\text { mento religioso }\end{array}$ & $8,7 \%$ & $28,7 \%$ & $20,0 \%$ & $33,8 \%$ & $8,7 \%$ \\
\hline $\begin{array}{l}\text { A união de duas pessoas tem que ser abençoada } \\
\text { pela Igreja }\end{array}$ & $7,1 \%$ & $18,9 \%$ & $13,8 \%$ & $37,8 \%$ & $22,4 \%$ \\
\hline \begin{tabular}{l} 
Alguém da Igreja inventou o casamento \\
\hline
\end{tabular} & $6,2 \%$ & $14,5 \%$ & $39,4 \%$ & $27,5 \%$ & $12,4 \%$ \\
\hline
\end{tabular}

Observa-se que os valores religiosos já não são tão importantes como motivo para o casamento. Porém uma grande parte dos respondentes considera que quem tem fé considera o casamento um ato sagrado $(73,5 \%)$ e que o casamento é muito valorizado pelas diferentes religióes (67,4\%). Quanto ao casamento como um compromisso com Deus e alguém da Igreja inventou o casamento, as opiniōes estão mais dispersas. As pessoas discordam de que a união de duas pessoas tem que ser abençoada pela Igreja $(60,2 \%)$ e quanto à obrigatoriedade do casamento religioso (42,5\%). Esses resultados corroboram a afirmação de alguns autores que sugerem uma redução do caráter sagrado do casamento (Paterniani, 1997; Jablonski, 2001). Nesse sentido, é importante lembrar que 49\% dos 
respondentes afirmaram não serem praticantes de suas religiões, sendo que a grande maioria é católica (80,2\%). Saraceno (2003) encontrou, entre os católicos praticantes, maior incidência de pessoas desfavoráveis à convivência não matrimonial como modelo alternativo ao casamento ou como fase que o precede. Considerando os motivos religiosos para o casamento, não foram encontradas diferenças estatísticas significativas entre os sexos.

Para verificar as expectativas quanto ao casamento, foram apresentados 11 itens e solicitado que ordenassem por prioridade, do mais importante ao menos importante, isto é, da $1^{\text {a à }} 11^{\text {a }}$ posição. Os resultados são apresentados a seguir:

- Companheirismo - maior concentração nas $1^{\mathrm{a}}$ e $2^{\mathrm{a}}$ posições $(60,6 \%)$.

- Quantidade amor e afeição - maior concentração entre $1^{\mathrm{a}} \mathrm{e}$ $3^{\mathrm{a}}$ posiçôes $(62,6 \%)$.

- Segurança emocional - maior concentração entre $2^{a}$ e $4^{a}$ posições $(44,7 \%)$.

- Crianças felizes e saudáveis - distribuição aproximadamente normal, predominando da $3^{a}$ à $7^{a}$ posição $(55,9 \%)$.

- Desenvolvimento da personalidade - maior concentração entre $3^{a}$ e $8^{a}$ posições $(64,2 \%)$.

- Manutenção de um lar - maior concentração entre $4^{a}$ e $9^{a}$ posições $(76,6 \%)$.

- Atividades de interesse comum - maior concentração entre $5^{\mathrm{a}}$ e $7^{\mathrm{a}}$ posições $(39,4 \%)$.

- Segurança econômica - maior concentração entre $6^{\mathrm{a}}$ e $10^{\mathrm{a}}$ posiçôes $(63,8 \%)$.

- Unidade religiosa e moral - maior concentração nas últimas posições, da $8^{\mathrm{a}}$ à $11^{\mathrm{a}}(41,8 \%)$.

- Lugar respeitável na comunidade - maior concentração nas últimas posições, da $9^{a}$ à $11^{\text {a }}(70,4 \%)$.

- Relações sexuais satisfatórias - distribuição uniforme entre todas as posições, da $1^{\text {a }}$ à $11^{\text {a }}$. 
Esses dados mostram que ocupam as primeiras posiçóes as expectativas relacionadas à relação amorosa: companheirismo e quantidade de amor e afeição. Aparecem, portanto, como expectativas mais importantes as relacionadas ao casamento contemporâneo, o qual se caracteriza pela maior valorização das trocas afetivas, da busca pela felicidade com um companheiro e pela intensidade dos sentimentos (Marodin, 1997; Coelho, 2000).

Entre as expectativas que ocupam uma posição intermediária, aparecem aquelas mais relacionadas ao casamento tradicional, isto é, ligadas à segurança emocional, manutenção de um lar, crianças felizes e saudáveis e segurança econômica, ao mesmo tempo em que aparecem expectativas voltadas para a relação: atividades de interesse comum e desenvolvimento da personalidade. Essas expectativas explicitam a concepção do casamento como uma forma de constituição de família atendendo aos anseios de ter filhos, construir um patrimônio e favorecer o desenvolvimento de todos os seus membros.

Ocupam as últimas posições as expectativas relacionadas aos aspectos sociais e religiosos: unidade religiosa e moral, e lugar respeitável na comunidade. Esses dados confirmam que, na contemporaneidade, os interesses individuais se sobrepõem aos sociais (Coelho, 2000; Féres-Carneiro, 2003; Jablonski, 2005).

Quanto à expectativa de relaçôes sexuais satisfatórias, foi a única que apresentou uma distribuição uniforme em todas as posições (da $1^{\mathrm{a}}$ à $11^{\mathrm{a}}$ ), o que demonstra que, para algumas pessoas, relações sexuais satisfatórias é a principal expectativa, enquanto que, para outras, é a de menor importância, não podendo ser considerado, nesse caso, um aspecto regulador da motivação para o casamento. $\mathrm{Na}$ avaliação das expectativas, observou-se uma tendência de as mulheres assinalarem essa expectativa como significativamente mais importante do que os homens ( $\mathrm{p}=0,053)$. Essa diferença pode ser entendida como consequência das mudanças no comportamento sexual das mulheres, que se tornaram mais exigentes tanto em relação à satisfação conjugal quanto à satisfação sexual. Já existem evidências (Diehl, 2002) que as mulheres estão exigindo mais sensualidade, erotismo, satisfação e prazer sexual de seus companheiros.

\section{Conclusões}

O casamento na contemporaneidade continua desejado, embora não esteja entre os principais projetos de vida dos adultos jovens solteiros. Atualmente é compreendido mais como algo que pode acontecer a qualquer momento do que como um objetivo a ser conquistado e pelo qual os jovens estejam 
dispostos a lutar para alcançá-lo. Observa-se que o casamento está ocorrendo mais tarde no ciclo evolutivo vital, sendo prioritários os investimentos na formação profissional, tanto para homens como para as mulheres. Outro aspecto importante na explicação desse fenômeno é a maior liberdade sexual para ambos os membros do casal, não sendo necessário se casar para ter uma vida sexual ativa.

Entre os motivos pessoais para o casamento, aparecem como mais fortes os vinculados à relação amorosa, à afinidade. Quanto aos motivos familiares, os adultos jovens indicam a expectativa e a importância que os pais atribuem ao casamento. Aparece também, com relevância, o desejo das mães de que os filhos se casem. Em relação aos motivos socioeconômicos, há maior concordância com o fato de oficializar uma união perante a sociedade. Entre os motivos religiosos, aparecem como mais significativos a valorização do casamento pelas diferentes religiões e o pressuposto de que quem tem fé considera o casamento como um ato sagrado.

Assim, observa-se que, entre os valores que permeiam a escolha pelo casamento, o amor, a família, os filhos e a religiosidade estão presentes para a maioria dos que participaram dessa pesquisa. Ainda que em segundo plano, uma vez que o casamento não ocupa lugar de destaque entre os projetos de vida, sendo prioritário o sucesso profissional e a realização pessoal.

Quanto às expectativas com relação ao casamento, os entrevistados manifestaram, especialmente, o companheirismo, o amor e a segurança emocional, isto é, fatores que se referem especificamente à relação afetivoemocional do casal (Garcia \& Tessara, 2001; Haddad, 2006). Isso reforça os resultados de outras investigações que apontam que, na atualidade, o casamento é baseado, principalmente, no desejo, nas expectativas e na satisfação dos cônjuges. Assim, a escolha pelo casamento na contemporaneidade é motivada, principalmente, por fatores subjetivos, predominando as expectativas referentes à qualidade da relação conjugal. Observa-se que os mesmos fatores que levam ao casamento são aqueles que também explicam a manutenção ou a ruptura do vínculo conjugal (Féres-Carneiro, 2003). A partir dessa perspectiva, constatase que, na contemporaneidade, o peso maior está colocado na relação que se estabelece entre os cônjuges e não no casamento como uma instituição, produto de um contrato religioso ou civil. Os aspectos familiares e sociais, que predominaram, historicamente, e foram tão importantes em outras épocas, são periféricos nesse novo contexto.

Constataram-se diferenças significativas entre os sexos quanto aos motivos pessoais e sociais para o casamento, além das expectativas. Os homens 
concordam, mais do que as mulheres, que ter espaço para o casal é um motivo para o casamento, talvez pelo maior desejo de independência e de separação da família de origem. É comum observar que, após o casamento, os homens se afastam de suas famílias e se vinculam mais às de suas esposas. Já as mulheres concordam mais com o motivo social de que casar é assumir um compromisso perante a sociedade, possivelmente porque há maior cobrança em relação aos comportamentos afetivo-sexuais delas que dos homens. Em relação às expectativas, relaçôes sexuais satisfatórias é o mais importante para as mulheres. Pode-se inferir que esses dados estejam associados a maior valorização que as mulheres estão dando para a sexualidade atualmente.

Dessa forma, conclui-se que as variáveis que definem a escolha pelo casamento em nossos dias envolvem aspectos de maior subjetividade e a manutenção ou a ruptura do contrato conjugal também está relacionada a esses aspectos. As pessoas não acreditam mais em expressões como: "casaram e foram felizes para sempre", mas passam a acreditar em casaram e ficaram casados enquanto se sentiam felizes. Como se pode constatar, a ideia de casamento permanece ligada à de amor. Sentimento de difícil definição, uma vez que, pelo caráter altamente subjetivo, pode ser explicado de diferentes formas. No próprio dicionário, o conceito de amor ocupa 74 linhas e refere 13 sentidos diferentes, podendo ser conceituado como "sentimento de dedicação absoluta de um ser a outro ser ou a uma coisa; devoção, culto, adoração", mas também como "amor passageiro e sem consequência, capricho" (Ferreira, 2004).

Ao analisar os motivos e expectativas com relação ao casamento, podemos observar aspectos tradicionais e contemporâneos que coexistem atualmente na vivência e na busca desse tipo de relacionamento. Sendo assim, os profissionais que se dedicam a trabalhar a conjugalidade devem estar atentos a esse contexto de diversidade e coexistência de modelos. De outro modo, o proselitismo ao novo tende a desconsiderar aspectos essenciais que têm perdurado ao longo do tempo nessas relações.

\section{Referências}

Araújo, M. F. (2002). Amor, casamento e sexualidade: velhas e novas configurações. Psicologia: Ciência e Profissão, 22 (2), 70-77.

Barich R. R. \& Bielby, D. (1996). Rethinking Marriage: change and statibility in expectations, 1967-1994. Journal of Family Issues, 17, 139-169. 
Bauman, Z. (2004). Amor líquido: sobre a fragilidade dos laços humanos. Rio de Janeiro: Zahar.

Bee, H. (1997). O ciclo vital. Porto Alegre: Artes Médicas.

Branden, N. (2000). La psicologia del amor romantico. Barcelona: Paidós.

Bueno, E. F. \& Prado, J. S. (1989). Educação emocional: a arte de unir-se. São Paulo: Cortez.

Cabral, A. (2006). Dicionário técnico de Psicologia. São Paulo: Cultrix.

Carter, B. \& McGoldrick, M. (2001). As mudanças no ciclo de vida familiar: uma estrutura para a terapia familiar. Porto Alegre: Artmed.

Coelho, S. V. (2000). As transformações da família no contexto brasileiro: uma perspectiva das relações de gênero. Psique, 10 (16), 7-24.

Costa, G. (2007). O amor e seus labirintos. Porto Alegre: Artmed.

Davis, A. (1998). Age differences in dating and marriage: reproductives strategies or social preferences. Current Antropology, 39 (3), 374-380.

Diehl, J. A. (2002). O homem e a nova mulher: novos padrões sexuais de conjugalidade. In: A. Wagner et al. Família em cena: tramas, dramas e transformaçōes. (p. 135-158). Petrópolis: Vozes.

Diniz Neto, O. \& Féres-Carneiro, T. (2005). Psicoterapia de casal na Pósmodernidade: rupturas e possibilidades. Estudos de Psicologia, 22 (2), Disponível em: <http://pepsic.bvs-psi.org.br/pdf/epc/v22n2/v22n2a03.pdf >. (Acesso em: 11 jul. 2009).

Erikson, E. H. (1994). Identity: youth and crisis. New York: WWNorton.

Féres-Carneiro, T. (1997). Escolha amorosa e interação conjugal na heterossexualidade e na homossexualidade. Psicologia: reflexão e crítica, 10 (2), 354-368.

Féres-Carneiro, T. (1998). Casamento contemporâneo: o difícil convívio da individualidade com a conjugalidade. Psicologia: reflexão e crítica, 11 (2), 379-394.

Féres-Carneiro, T. (2003). Construção e dissolução do laço conjugal. In: T. FéresCarneiro et al. Familia e casal: arranjos e demandas contemporâneas. (p. 210-214). Rio de Janeiro: PUC-Rio. 
Ferreira, A. B. (2004). Novo dicionário Aurélio da língua portuguesa. Curitiba: Positivo.

Garcia-Vega, L. \& Ríos-Gonzalez, J. A. (1999). Amory convivencia:psicoterapia de la vida de pareja y sistema familiar. Valencia: Promolibro.

Garcia, M. L. T. \& Tessara, E. T. O. (2001). Estratégias de enfrentamento do cotidiano conjugal. Psicologia: reflexão e crítica, 14 (2) 635-642.

Goldenberg, M. (1991). Ser homem, ser mulher: dentro e fora do casamento. Rio de Janeiro: Revan.

Goldenberg, M. (2004). De perto ninguém é normal: estudo sobre corpo, sexualidade, gênero e desvio na cultura brasileira. Rio de Janeiro: Record.

Gomes, I. C. \& Paiva, M. L. de S. C. (2003). Casamento e família no século XXI: possibilidade de holding? Psicologia em Estudo, 8. Disponível em: <http://www.scielo.br/scielo.php?script=sci_arttext\&pid=S141373722003000300002>. (Acesso em: 11 jul. 2009).

Gray, J. (1997). Homens são de Marte, mulheres são de Vênus. Rio de Janeiro: Rocco.

Hadadd, G. (2006). Reflexôes sobre a manutenção do ideal de amor romântico na atualidade: um estudo sobre a fidelidade conjugal. Dissertação de mestrado, Programa de Pós-graduação em Psicologia, Universidade de São Marcos, São Paulo.

Heilborn, M. L. (1995). O que faz um casal, casal? Conjugalidade, igualitarismo e identidade sexual em camadas médias e urbanas. In: I. Ribeiro $\&$ A. C. Ribeiro et al. Família em processos contemporâneos: inovaçôes culturais na sociedade contemporânea. (p. 91-96). São Paulo: Loyola.

Heilborn, M. L. (2004). Dois é par: gênero e identidade sexual em contexto igualitário. Rio de Janeiro: Garamond.

Henriques, C. R.; Jablonski, B. \& Féres-Carneiro, T. (2004). A "geração canguru": algumas questôes sobre o prolongamento da convivência familiar. Psico, 35 (2), 195-205.

Henriques, C. R.; Féres-Carneiro, T. \& Magalhães A. S. (2006). Trabalho e família: o prolongamento da convivência familiar em questão. Paideia, 16 (35), 327-336. 
Jablonski, B. (2001). Atitudes frente à crise do casamento. In: T. FéresCarneiro et al. Casamento e família: do social à clínica. (p. 81-95). Rio de Janeiro: Nau.

Jablonski, B. (2005). Atitudes de jovens solteiros frente à família e ao casamento: novas tendências? In: T. Féres-Carneiro et al. Familia e casal: efeitos da contemporaneidade. (p. 93-110). Rio de Janeiro: PUC-Rio.

Magalhães, A. (2003). Transmutando a subjetividade na conjugalidade. In: T. Féres-Carneiro et al. Familia e casal: arranjos e demandas contemporâneas. (p. 225-245). Rio de Janeiro: PUC-Rio.

Marodin, M. (1997). As relações entre o homem e a mulher na atualidade. In: M. N. Strey et al. Mulher estudos de gênero. (p. 9-18). São Leopoldo: Ed. Unisinos.

Menezes, C. C. \& Lopes, R.C.S. (2007). A transição para o casamento em casais coabitantes e casais não coabitantes. Revista Brasileira Desenvolvimento Humano, 17 (1), p. 52-63.

Mezan, R. (2003). Adão e sua costela: busca da felicidade e crise atual do casamento. In: p. B. Gomes et al. Vinculos amorosos contemporâneos. (p. 159171). São Paulo: Callis.

Morris, C. G. \& Maisto, A. A. (2004). Introdução à Psicologia. São Paulo: Prentice Hall.

Munhoz, M. L. P. (2004). Casamento: ruptura ou continuidade dos modelos familiares. São Paulo: Expressão e Arte.

Moraes, V. (1992). Antologia poética. São Paulo: Companhia das Letras.

Orsolin, R. (2004). Nem toda mulher quer ser mãe: novas configurações do feminino. In: C. M. B. Cenci, M. Piva \& V. R. T. Ferreira et al. Relaçôes Familiares: uma reflexão contemporânea. (p. 74-88). Passo Fundo: UPF.

Papalia, D.; Olds, S. \& Feldman, R. (2006). Desenvolvimento humano. Porto Alegre: Artmed.

Paterniani, A. L. S. (1997). A aventura amorosa do casal contemporâneo. Revista da Sociedade Brasileira de Sexualidade Humana, 8 (1), 46-60.

Pincus, L. \& Dare, C. (1981). Psicodinâmica da família. Porto Alegre: Artes Médicas. 
Rampage, C. (1995). Poder, sexos e intimidade conjugal. Insight Psicoterapia, $8-13$.

Rossi, C. (2003). Os novos vínculos conjugais: vicissitudes e contradições. In:

P. B. Gomes et al. Vinculos amorosos contemporâneos. (p. 77-108). São Paulo: Callis.

Saraceno, C. (2003). Sociologia da familia. Lisboa: Estampa.

Severino, R. S. (1996). Casais construindo seus caminhos: a terapia de casal e a família de origem. In: L. C. Prado et al. Familias e terapeutas construindo caminhos. (p. 71-96). Porto Alegre: Artes Médicas.

Silveira, P. G. \& Wagner, A. (2006). Ninho cheio: a permanência do adulto jovem em sua família de origem. Estudos em Psicologia, 23 (4), 441-453.

Straube, K. M., Gonçalves, M. de P. \& Centa, M. de L. (2003). Percepção dos filhos sobre o divórcio dos pais. Família Saúde Desenvolvimento, 5 (3), 173-184.

Turkenicz, A. (1995). A aventura do casal. Porto Alegre: Artes Médicas.

Wagner, A.; Falcke, D. \& Meza, E, B. (1997). Crenças e valores dos adolescentes acerca de família, casamento, separação e projetos de vida. Psicologia: reflexão e crítica, 10 (1), 155-167.

Wendling, M. I. (2002). "Asas para voar, raizes para voltar": a saída dos filhos da casa dos pais. Dissertação de mestrado, Programa de Pós-graduação em Psicologia, Pontifícia Universidade Católica do Rio Grande do Sul, Porto Alegre.

Zagury, T. (1999). O adolescente por ele mesmo. Rio de Janeiro: Record. 